\title{
The modified Fontan procedure: Early and late results in 132 adult patients
}

Harold M. Burkhart, $\mathrm{MD}^{\mathrm{a}}$

Joseph A. Dearani, MD

Douglas D. Mair, MD ${ }^{\mathrm{b}}$

Carole A. Warnes, MD ${ }^{\mathrm{C}}$

Charles C. Rowland ${ }^{\mathrm{d}}$

Hartzell V. Schaff, MD ${ }^{a}$

Francisco J. Puga, MDa

Gordon K. Danielson, MD ${ }^{\mathrm{a}}$

From the Division of Cardiovascular Surgery, ${ }^{\mathrm{a}}$ Section of Pediatric Cardiology, ${ }^{\mathrm{b}} \mathrm{Di}$ vision of Cardiovascular Diseases, ${ }^{\mathrm{c}}$ and Division of Biostatistics, ${ }^{\mathrm{d}}$ Mayo Clinic and Mayo Foundation, Rochester, Minn.

Read at the Eighty-second Annual Meeting of The Association for Thoracic Surgery, Washington, DC, May 5-8, 2002.

Received for publication June 6, 2002; revisions received Nov 12, 2002; accepted for publication Nov 25, 2002.

Address for reprints: Joseph A. Dearani, MD, Mayo Clinic, 200 First Street SW, Rochester, MN 55905 (E-mail: jdearani@ mayo.edu).

J Thorac Cardiovasc Surg 2003;125:1252-9

Copyright $\odot 2003$ by The American Association for Thoracic Surgery

$0022-5223 / 2003 \$ 30.00+0$

doi:10.1016/S0022-5223(03)00117-X

Objective: The modified Fontan procedure, usually performed in children, is used for the treatment of anomalies with a single functional ventricle. We reviewed our experience with the modified Fontan procedure performed in the adult patient.

Methods: Between October 1973 and May 2001, the modified Fontan procedure was performed on 132 adult patients ( 74 men, 58 women). Median age was 23 years (range, 18 to 53 years). Diagnoses included tricuspid atresia in 34 patients $(26 \%)$, double-inlet left ventricle in $48(36 \%)$, and complex lesions in $50(38 \%)$. The majority of patients $(89 \%)$ had at least one prior palliative procedure; the most common procedures were Blalock-Taussig shunt in 85 patients and Glenn anastomosis in 31 .

Results: Operations included an atriopulmonary connection in 74 patients, lateral tunnel in 27, intra-atrial conduit in 14, right atrium-to-right ventricle in 9, extracardiac conduit in 3 , and other in 5 . Overall early mortality was $8.3 \%$. Mortality was $6.5 \%$ for operations performed after 1980 . This is comparable to the mortality of the modified Fontan procedure performed in children during the same time interval at our institution. All 7 of the early deaths since 1980 occurred in the complex lesion group. Morbidity included prolonged pleural effusion in 36 patients, atrial arrhythmias in 25 , reoperation for bleeding in 13 , permanent pacemaker in 8 , and stroke in 2. Mean follow-up was 9.1 years with a maximum of 21.2 years. Actuarial survival for early survivors was $89 \%(84,95), 75 \%(67,84)$, and $68 \%(58,79)$ at 5,10 , and 15 years, respectively. Freedom from late reoperation was $89 \%(83,95), 85 \%(78,93)$, and $80 \%(70,91)$ at 5,10 and 15 years, respectively. The majority $(90 \%)$ of present survivors were New York Heart Association class I or II at follow-up.

Conclusions: In properly selected adult patients with functional single ventricle, the modified Fontan procedure can be performed with early mortality similar to younger patients. Early mortality is more likely with complex lesions. The majority of late survivors have a good quality of life.

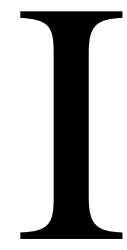

n 1971 Fontan and Baudet first described successful clinical bypass of the right ventricle, with separation of the pulmonary and systemic circulations, in a patient with tricuspid atresia. ${ }^{1}$ The technique described in this initial report included a classic Glenn anastomosis, a pulmonary homograft valve inserted at the inferior vena cava-right atrial junction, and an aortic valved homograft from the right atrial appendage to the main pulmonary artery. Independently, Kreutzer and colleagues described right ventricle bypass in a patient 
TABLE 1. Diagnoses

\begin{tabular}{lcc}
\hline Diagnosis & n & \% of total \\
\hline Tricuspid atresia & 34 & 26 \\
Double-inlet left ventricle & 48 & 36 \\
Complex & 50 & 38 \\
$\quad$ Double-outlet right ventricle & 20 & \\
UVH, common AV valve & 9 & \\
UVH, left AV valve atresia & 7 & \\
UVH, right AV valve atresia & 7 & \\
Hypoplastic right heart & 3 & \\
Double-inlet right ventricle & 2 & \\
Hypoplastic left heart & 2 &
\end{tabular}

$A V$, Atrioventricular; $U V H$, univentricular heart.

with tricuspid atresia in which the pulmonary annulus and valve were detached from the right ventricular outflow tract and connected to the right atrial appendage. ${ }^{2}$ Since these initial reports, the operative technique has gone through many technical modifications and has been applied to patients with a variety of functional single-ventricle diagnoses. Since 1973, we have performed several modifications of the Fontan procedure (MFP) in patients with tricuspid atresia, double-inlet left ventricle, and other forms of complex functional single ventricle. Historically, the operation has been performed predominantly in children. The purpose of this study was to examine the clinical course and outcome of all adult patients who had an MFP performed at the Mayo Clinic.

\section{Patients and Methods}

MFP was performed in 957 patients from October 31, 1973, to April 24, 2001, at the Mayo Clinic in Rochester, Minnesota. One hundred thirty-two of these patients (14\%) were 18 years of age or older. Medical records of these 132 adult patients were reviewed for patient demographics, preoperative symptoms, operative procedure, pre- and postoperative hemodynamics, early and late morbidity, and survival. Adult patients undergoing revision of a previous MFP were excluded from this study.

Seventy-four patients $(56 \%)$ were men and 58 (44\%) were women. Median age at time of the MFP was 23 years (range, 18 to 53 years). The majority of patients $(85 \%)$ were in New York Heart Association (NYHA) functional class III or IV preoperatively. Fifty patients (38\%) were on preoperative digoxin, 20 (15\%) were on diuretic therapy, and $15(11 \%)$ were on an antiarrhythmic agent.

Diagnoses were divided into three groups as seen in Table 1. All of the patients in the complex lesion group had a functional single ventricle or two ventricles unsuitable for ventricular septation. The subset of patients with double-outlet right ventricle included asplenia and polysplenia syndromes, hypoplastic or straddling atrioventricular valves, and crisscross hearts, all of which had anomalies that precluded a two-ventricle repair.

A total of 193 palliative operations had been performed prior to the MFP in 118 patients (89\%) (Table 2). The two most common procedures were Blalock-Taussig shunt $(\mathrm{n}=85)$ and Glenn anastomosis $(\mathrm{n}=31)$. A Potts or Waterston anastomosis was per-
TABLE 2. Prior palliative procedures*

\begin{tabular}{lr}
\hline Procedures & $\mathbf{n}$ \\
\hline Blalock-Taussig & 85 \\
Glenn & 31 \\
Pulmonary artery banding & 20 \\
Waterston & 19 \\
Potts & 16 \\
Exploration & 5 \\
Atrial septectomy & 5 \\
Pulmonary valvotomy & 3 \\
Subaortic resection & 3 \\
Central shunt & 2 \\
Damus-Stansel-Kaye & 1 \\
Brock & 1 \\
Atrial septal defect closure & 1 \\
Atrioventricular valve repair & 1 \\
None & 14 \\
Total & 193 \\
\hline
\end{tabular}

*Some patients had more than one procedure.

formed in 35 patients. Sixty patients had one previous operation, 46 had two, and 12 had three or more. Fourteen patients (11\%) had no cardiac operations prior to their MFP.

Prolonged pleural effusions were defined as effusions that required chest tube drainage for more than 14 days. Atrial arrhythmias included transient or persistent supraventricular tachycardia, atrial fibrillation, and atrial flutter. Renal failure was defined as occurring in patients who required hemodialysis.

The follow-up status of the patients was determined principally by review of the patient records, written questionnaires, or telephone interviews when necessary. Data reviewed included functional status, any hospitalizations, cardiovascular events, and reoperations. Death certificates, physician notes, and hospital notes were reviewed in the event of a death.

Early mortality was defined as death occurring within 30 days of operation or at any time during the operative hospitalization. Survival statistics were performed using the Kaplan-Meier method with the day of operation as the starting point. ${ }^{3}$ Ninety-five percent confidence intervals were calculated for each survival estimate. Survival curves were compared using the log-rank test. Factors that affected survival were analyzed with the Cox proportional hazards model. ${ }^{4}$ Continuous risk factors were dichotomized using roughly the median or third quartile as a cut point. $P$ values less than .05 were considered statistically significant.

\section{Results}

All operations were performed through a median sternotomy utilizing cardiopulmonary bypass. The median cardiopulmonary bypass time was 138 minutes (range, 66 to 339 minutes). Aortic crossclamping was utilized in 121 patients (92\%) for a median time of 70 minutes (range, 6 to 194 minutes). Circulatory arrest with deep hypothermia was used in 14 patients $(11 \%)$. Available preoperative and postoperative hemodynamic measurements are reported in Table 3 . The modifications of the Fontan procedure performed are shown in Table 4. Associated cardiac procedures per- 
TABLE 3. Pre- and postoperative hemodynamic variables

\begin{tabular}{|c|c|c|c|c|}
\hline Variable & $\mathbf{n}$ & Mean + SD & Median & Range \\
\hline \multicolumn{5}{|l|}{ Preoperative } \\
\hline Ejection fraction (\%) & 90 & $55 \pm 9.7$ & 54 & $34-88$ \\
\hline Right atrial pressure $(\mathrm{mm} \mathrm{Hg})$ & 124 & $8.2 \pm 4.1$ & 8 & $1-20$ \\
\hline $\begin{array}{l}\text { Pulmonary artery pressure } \\
(\mathrm{mm} \mathrm{Hg})\end{array}$ & 118 & $15 \pm 7.2$ & 14 & $2-37$ \\
\hline \multicolumn{5}{|l|}{ Postoperative } \\
\hline Right atrial pressure $(\mathrm{mm} \mathrm{Hg})$ & 129 & $17 \pm 3.2$ & 17 & $8-25$ \\
\hline Left atrial pressure $(\mathrm{mm} \mathrm{Hg})$ & 128 & $10 \pm 3.0$ & 10 & $3-17$ \\
\hline $\begin{array}{l}\text { Transpulmonary gradient } \\
(\mathrm{mm} \mathrm{Hg})\end{array}$ & 128 & $7 \pm 2.7$ & 7 & $2-15$ \\
\hline
\end{tabular}

\section{TABLE 4. Type of modified Fontan connection}

\begin{tabular}{lrc}
\hline Connection & $\mathbf{n}$ & \% of total \\
\hline Atriopulmonary & 74 & 56 \\
Lateral tunnel & 27 & 20 \\
$\quad$ Atriopulmonary connection & 22 & 17 \\
$\quad$ Total cavopulmonary connection & 5 & 4 \\
Intra-atrial conduit & 14 & 11 \\
Right atrium-to-right ventricle & 9 & 7 \\
Extra-cardiac conduit & 3 & 2 \\
Other & 5 & 4 \\
\hline
\end{tabular}

formed at the time of the MFP, other than takedown of shunts, atrial septal defect closures, and main pulmonary artery closures, are listed in Table 5. Only 2 patients had an atrial fenestration.

Overall early mortality was $8.3 \%$ (11 patients). Seven of the deaths were cardiac in origin (Table 6). Other causes included sepsis in 2, pulmonary hypertension in 1 , and pulmonary embolism in 1 . Overall early mortality was $6.5 \%$ (7/108) for operations performed after 1980. All 7 of the early deaths since 1980 occurred in the complex lesion group. There has been no early mortality in adult patients with double-inlet left ventricle $(\mathrm{n}=36)$ or tricuspid atresia $(n=25)$ who were operated on after 1980. Univariate analysis did not demonstrate any statistically significant risk factors for early mortality (Table 7), although mean postoperative right atrial pressure greater than $20 \mathrm{~mm} \mathrm{Hg}(P=$ .06) approached statistical significance. Of note, patients with ventricular ejection fractions greater or equal to $50 \%$ or atriopulmonary connections appeared to have less risk for early mortality $(P=.06)$. Multivariate analysis could not be performed due to the low number of events.

Median hospital stay was 15 days (range, 6 to 82 days). Seventy-six of the 121 early survivors (63\%) experienced nonfatal postoperative morbidity (Table 8 ). The two most common morbidities included prolonged pleural effusions (30\%) and atrial arrhythmias (21\%). The two "Other" reoperations were for repair of atrial septal defect patch dehiscence and removal of retained atrial pacing wires, respectively.
TABLE 5. Additional procedures at time of the modified Fontan procedure

\begin{tabular}{lcc}
\hline Procedure & n & \% of total \\
\hline Right atrioventricular valve patch closure & 44 & 33 \\
Pulmonary artery patch angioplasty & 17 & 13 \\
Atrioventricular valve repair & 10 & 8 \\
Atrioventricular valve replacement & 5 & 4 \\
Aortic valve replacement & 2 & 1.5 \\
Atrial fenestration & 2 & 1.5 \\
Damus-Stansel-Kaye anastomosis & 1 & 0.8 \\
\hline
\end{tabular}

The mean follow-up for the 121 hospital survivors was 9.1 years with a maximum of 21.2 years. Three foreign patients were lost to follow-up. There were 32 known late deaths, occurring from 1.1 months to 18 years after operation. The most common causes of late mortality were failure of the univentricular circulation and arrhythmia (Table 9). Kaplan-Meier survival, excluding early mortality, was $89 \%$ $(84,95), 75 \%(67,84)$, and $68 \%(58,79)$ at 5,10 , and 15 years, respectively (Figure 1). Survival stratified according to initial diagnosis is shown in Figure 2. Univariate analysis for late mortality is shown in Table 10. Significant risk factors included preoperative mean pulmonary artery pressure $>15 \mathrm{~mm} \mathrm{Hg}$, male gender, age $>30$ years, and postoperative right atrial pressure $>20 \mathrm{~mm} \mathrm{Hg}$. Of interest, patients who underwent an MFP with an atriopulmonary connection were found to have a significantly lower risk of late mortality. Significant risk factors by multivariate analysis are shown in Table 11.

Fifteen patients underwent late reoperation (Table 12). No patient died at reoperation. Freedom from late reoperation was $89 \%(83,95), 85 \%(78,93)$, and $81 \%(70,91)$ at 5 , 10, and 15 years, respectively (Figure 3). Univariate analysis demonstrated operation prior to 1981 as a risk factor for reoperation $(P=.01)$. Multivariate analysis was not performed due to too few reoperations.

Information on late complications was available in the majority of hospital survivors (110 patients, $91 \%$ ). Arrhythmias were present in 46 patients (42\%); 36 patients (33\%) had atrial arrhythmias. The initial operations in these 36 patients with late atrial arrhythmias included atriopulmonary connection in 28 patients, lateral tunnel with atriopulmonary connection in 3 , right atrium-to-right ventricle connection in 3, intra-atrial conduit in 1 , and a Glenn shunt with a right atrium-to-left pulmonary artery conduit in 1 . Sixteen patients (15\%) had received permanent pacemakers secondary to chronotropic insufficiency or complete heart block, including heart block resulting from catheter ablation. Other late complications included protein-losing enteropathy in 8 patients, pleural effusion requiring thoracentesis in 7 , and cerebrovascular accident in 4 (none of the 4 were anticoagulated). Of the 89 presently surviving patients, NYHA func- 
TABLE 6. Cardiac causes of early death

\begin{tabular}{|c|c|c|c|c|c|c|}
\hline Diagnosis & $\begin{array}{c}\text { Age } \\
\text { (year) }\end{array}$ & Operation & $\begin{array}{c}\text { Surgery } \\
\text { (year) }\end{array}$ & $\begin{array}{l}\text { Preop } \\
\text { PAP }\end{array}$ & $\begin{array}{l}\text { Postop } \\
\text { RAP }\end{array}$ & Death history \\
\hline Complex & 19 & LT, APC & 1987 & 13 & 18 & Progressive heart failure, takedown Fontan \\
\hline Complex & 21 & Intra-atrial conduit & 1990 & 21 & 11 & Morphologically right ventricle, cardiac failure \\
\hline DILV & 21 & APC & 1979 & 17 & 25 & Difficulty coming off bypass, cardiac failure \\
\hline TA & 22 & RA-PA, IVC valve & 1976 & 7 & 17 & Thrombosed IVC due to pulmonary HTN, cardiac failure \\
\hline Complex & 24 & LT, TCPC & 1990 & 35 & 16 & Spontaneous dissection of right coronary artery ostium \\
\hline Complex & 29 & $\mathrm{LT}, \mathrm{APC}$ & 1985 & 9 & 18 & Anomalous hepatic veins, cyanosis, failure to come off bypass \\
\hline Complex & 35 & LT, APC & 1990 & 9 & 17 & Morphologically right ventricle, cardiac failure \\
\hline
\end{tabular}

$A P C$, Atriopulmonary connection; DILV, double-inlet left ventricle; $H T N$, hypertension; $I V C$, inferior vena cava; $L T$, lateral tunnel; $P A P$, mean pulmonary artery pressure $(\mathrm{mm} \mathrm{Hg}) ; R A P$, mean right atrial pressure $(\mathrm{mm} \mathrm{Hg}) ; R A-P A$, right atrium-to-pulmonary artery conduit; $T A$, tricuspid atresia; $T C P C$, total caval-pulmonary connection.

TABLE 7. Univariate analysis for early mortality

\begin{tabular}{llll}
\hline Variable & $\begin{array}{c}\text { Hazard } \\
\text { ratio }\end{array}$ & $\begin{array}{c}\mathbf{9 5 \%} \text { Cl } \\
\text { value }\end{array}$ \\
\hline Ejection fraction $\geq 0.50$ & 0.23 & $0.05-1.1$ & .06 \\
Postoperative RAP $>20 \mathrm{~mm} \mathrm{Hg}$ & 4.1 & $0.93-17.7$ & .06 \\
Atriopulmonary connection & 0.26 & $0.07-1.0$ & .06 \\
MFP after 1980 & 0.35 & $0.09-1.3$ & .12 \\
Postoperative LAP $>10 \mathrm{~mm} \mathrm{Hg}$ & 2.4 & $0.60-9.4$ & .22 \\
Prolonged pleural effusion & 0.30 & $0.04-2.4$ & .26 \\
Preoperative PAP $>15 \mathrm{~mm} \mathrm{Hg}$ & 1.9 & $0.55-6.7$ & .30 \\
Age $>30$ years & 0.38 & $0.05-3.1$ & .37 \\
Aortic crossclamp time $\geq 90 \mathrm{minutes}$ & 1.7 & $0.46-6.1$ & .44 \\
Male & 0.63 & $0.18-2.2$ & .46 \\
CPB time $\geq 180$ minutes & 1.5 & $0.37-6.1$ & .56 \\
NYHA functional class III or IV & 1.8 & $0.21-14.6$ & .60 \\
Preoperative RAP $>10 \mathrm{~mm} \mathrm{Hg}$ & 0.73 & $0.15-3.7$ & .70 \\
Previous surgery & 1.2 & $0.14-10.2$ & .86
\end{tabular}

$C l$, Confidence interval; $C P B$, cardiopulmonary bypass; $L A P$, mean left atrial pressure; MFP, modified Fontan procedure; NYHA, New York Heart Association; $P A P$, mean pulmonary artery pressure; $R A P$, mean right atrial pressure.

tional class was available in $80(90 \%)$. There were 33 patients $(41 \%)$ in class I, $39(49 \%)$ in class II, $7(9 \%)$ in class III, and $1(1 \%)$ in class IV.

\section{Discussion}

Definitive palliation for anomalies with a single functional ventricle, or two ventricles with anatomy that precludes ventricular septation, has been successfully accomplished by separation of the pulmonary and systemic circulations. ${ }^{1,2}$ Many modifications of the original procedures have been made. Although the majority of the literature describes the outcome of children undergoing an MFP, adult patients may present with no or unsatisfactorily palliated single-ventricle physiology. We have previously reported our results with a small number of adult MFP patients from our early experience. ${ }^{5,6}$ This report examines the late results of all adult patients who underwent MFP at our institution over a 28 year period.

\section{TABLE 8. Early nonfatal morbidity}

\begin{tabular}{lcc}
\hline Complication & $\mathbf{n}$ & \% of total \\
\hline Prolonged pleural effusion & 36 & 30 \\
Atrial arrhythmias & 25 & 21 \\
Early reoperation & 13 & 11 \\
$\quad$ Bleeding & 11 & 9 \\
Other & 2 & 1.7 \\
Permanent pacemaker & 8 & 7 \\
Pneumonia & 6 & 5 \\
Renal failure & 3 & 2.5 \\
Cardiac arrest (surviving) & 3 & 2.5 \\
Tamponade & 2 & 1.7 \\
Cerebral vascular accident & 2 & 1.7 \\
Tracheostomy & 1 & 0.8 \\
Sternal wound infection & 1 & 0.8 \\
Gastrointestinal hemorrhage & 1 & 0.8 \\
Colitis & 1 & 0.8
\end{tabular}

\section{TABLE 9. Causes of late mortality}

\begin{tabular}{lr}
\hline Cause & $\mathbf{n}$ \\
\hline Congestive heart failure & 6 \\
Sudden/arrhythmia & 5 \\
Protein-losing enteropathy & 3 \\
Sepsis & 3 \\
Pulmonary embolism & 1 \\
Inferior vena cava thrombosis & 1 \\
Tuberculosis & 1 \\
Appendectomy complication & 1 \\
Accident & 1 \\
Unknown & 10 \\
Total & 32 \\
\hline
\end{tabular}

Our philosophy regarding patient selection has evolved over the past 3 decades. Early in our experience, we recognized that the criteria for operability suggested by Choussat and Fontan were too strict and excluded patients who could potentially be helped with an MFP. ${ }^{7}$ Accordingly, we liberalized our criteria for selected patients. ${ }^{8,9}$ The previously recommended upper limit of age (15 years) was exceeded in 
TABLE 10. Univariate analysis for late mortality

\begin{tabular}{llcc}
\hline Variable & $\begin{array}{c}\text { Hazard } \\
\text { ratio }\end{array}$ & 95\% Cl & $\boldsymbol{P}$ value \\
\hline Preoperative PAP $>15 \mathrm{~mm} \mathrm{Hg}$ & 3.8 & $1.7-8.4$ & .001 \\
Male & 2.8 & $1.2-6.6$ & .01 \\
Age $>30$ years & 2.3 & $1.1-4.8$ & .04 \\
Postoperative RAP $>20 \mathrm{~mm} \mathrm{Hg}$ & 2.4 & $0.99-6.0$ & .05 \\
APC & 0.5 & $0.25-1.0$ & .05 \\
NYHA functional class 3 or 4 & 4.6 & $0.63-34$ & .13 \\
Preoperative RAP $>10 \mathrm{~mm} \mathrm{Hg}$ & 1.7 & $0.83-3.7$ & .14 \\
CPB time $\geq 180$ minutes & 1.8 & $0.79-4.0$ & .16 \\
Fontan after 1980 & 0.61 & $0.29-1.3$ & .21 \\
Prolonged pleural effusion & 1.4 & $0.67-2.8$ & .39 \\
Transpulmonary gradient $\geq 10 \mathrm{~mm} \mathrm{Hg}$ & 1.5 & $0.46-5.1$ & .48 \\
Postoperative LAP $>10 \mathrm{~mm} \mathrm{Hg}$ & 1.3 & $0.56-2.8$ & .52 \\
Aortic crossclamp time $\geq 90 \mathrm{minutes}$ & 1.2 & $0.54-2.7$ & .66 \\
Previous surgery & 1.2 & $0.36-3.9$ & .77 \\
Ejection fraction $\geq 0.50$ & 0.87 & $0.30-2.5$ & .79
\end{tabular}

$A P C$, Atriopulmonary connection without lateral tunnel; $\mathrm{Cl}$, confidence interval; $C P B$, cardiopulmonary bypass; $L A P$, mean left atrial pressure; $N Y H A$, New York Heart Association; $P A P$, mean pulmonary artery pressure; $R A P$, mean right atrial pressure.

TABLE 11. Multivariate analysis of risk factors for late mortality

\begin{tabular}{lccc}
\hline Variable & $\begin{array}{c}\text { Hazard } \\
\text { ratio }\end{array}$ & $\mathbf{9 5 \%}$ Cl & $\boldsymbol{P}$ value \\
\hline Preoperative PAP $>15 \mathrm{~mm} \mathrm{Hg}$ & 3.5 & $1.5-8.1$ & .0005 \\
Age $\geq 30$ years & 2.9 & $1.2-6.7$ & .01 \\
Male gender & 3.4 & $1.2-10.1$ & .03
\end{tabular}

$\mathrm{Cl}$, Confidence interval; $P A P$, mean pulmonary artery pressure.

\section{TABLE 12. Late reoperations}

Procedure
Repair tricuspid valve patch dehiscence
Revision of stenotic RA-PA connection
Atrioventricular valve replacement
Conversion APC to lateral tunnel with APC
Conversion to unvalved 1.5 ventricle repair; cryomaze
Removal of infected epicardial pacemaker leads
Revision of SVC-RA anastomosis
Removal of thrombosed intra-atrial (hepatic veins)
conduit

Total

$\overline{A P C}$, Atriopulmonary connection; $R A-P A$, right atrium-to-right ventricle; $S V C-R A$, superior vena cava-to-right atrium.

all patients in this review. The anatomical and cardiac rhythm criteria of operability such as normal drainage of the venae cavae, normal volume of the right atrium, no mitral insufficiency, and sinus rhythm were also exceeded in many patients. In addition, hemodynamic criteria regarding ventricular function and mean pulmonary artery pressure were

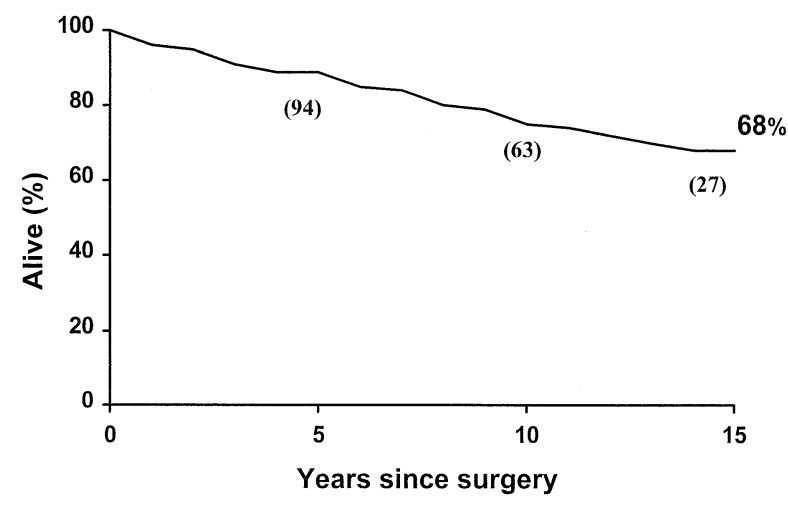

Figure 1. Kaplan-Meier curve for survival excluding early mortality. $\mathbf{n}=$ number of patients at risk.

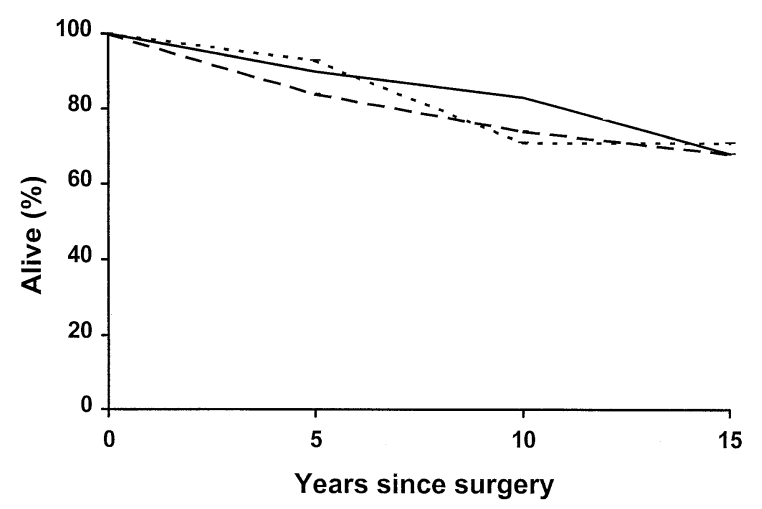

Figure 2. Kaplan-Meier curves for survival, excluding early mortality, divided into diagnoses: tricuspid atresia (solid line), double-inlet left ventricle (dotted line), and complex (dashed line). There was no statistically significant difference in the 15 -year survival between the groups. $n=$ number of patients at risk.

exceeded in approximately half of the patients, as shown in Table 3 (mean ventricular ejection fraction was 55\%, and mean pulmonary artery pressure was $15 \mathrm{~mm} \mathrm{Hg}$ ).

Most patients (85\%) were in NYHA functional class III or IV, and the vast majority were experiencing progressive decrease in exercise tolerance and quality of life. Objective progressive decline in ventricular function, decline in arterial oxygen saturation, or increase in atrioventricular valve regurgitation were other factors that were considered. Selected deteriorating patients who were recognized to be at significantly increased risk for operation and for whom no other surgical options were available were offered operation if it was thought there was a reasonable chance for their survival and improvement, and some such patients had excellent late results. However, it is still often difficult to determine with confidence which adult patients who exceed accepted criteria for operability might be benefited by an MFP and which should not be offered operation. Elevated 
pulmonary arteriolar resistance and severe systolic and diastolic ventricular dysfunction have been found to be the most important contraindications to the MFP. ${ }^{8,9}$ In general, the indications and criteria employed for adults in this series were the same as for children at our institution.

Early mortality was $8.3 \%$ for the entire group of 132 patients. Over half of the early deaths were due to cardiac causes. The early mortality declined after 1980 to $6.5 \%$. Similar early mortality rates ranging from $5 \%$ to $13 \%$ have been reported in adult MFP patients. ${ }^{10-12}$ Of note is that the mortality of our adult series is comparable to mortality of the MFP performed in children at our institution as well as other institutions. ${ }^{13-16}$ Mair and coworkers reported an early mortality of $9 \%$ in a cohort of patients, the majority of whom (88\%) were 19 years old or younger. ${ }^{13}$ All 7 of the early deaths since 1980 in the present study occurred in patients with complex anatomy; there was no early mortality in adult patients with double-inlet left ventricle $(n=36)$ or tricuspid atresia $(n=25)$. Overall in this study, there has been only 1 early death in all 34 patients (2.9\%) with a diagnosis of tricuspid atresia.

Important postoperative morbidity occurred in $63 \%$ of the patients. The most common was chest tube drainage longer than 14 days, occurring in $30 \%$. We and others have reported similar postoperative pleural effusion rates in children and adults. ${ }^{11,17}$ Many of our patients were operated on prior to the introduction of the fenestration concept. Nevertheless, we apply the fenestration selectively for patients with findings that the attending cardiologist and surgeon anticipate will increase the probability for postoperative morbidity or mortality, especially if hemodynamics are borderline at the conclusion of the MFP. If a fenestration is performed in an adult patient, warfarin anticoagulation is usually recommended. The long-term risks associated with chronic right-to-left shunting, thrombus formation, and potential paradoxical embolism have been the major concerns associated with fenestration, especially in adult patients. ${ }^{17}$ In addition, there is the decrease in exercise tolerance, and consequently quality of life, in fenestrated patients with arterial desaturation.

The second most common postoperative morbidity was atrial arrhythmias, occurring in $21 \%$ of the patients. This is consistent with other mixed-aged cohorts showing a $10 \%$ to $20 \%$ incidence of atrial arrhythmias in the postoperative period. ${ }^{18-20}$ Of note is that 16 of the 25 patients who experienced atrial arrhythmias had an atriopulmonary connection without lateral tunnel. Newer MFP modifications such as the extracardiac conduit MFP, which has fewer atrial suture lines as well as decreased atrial wall tension, may reduce the incidence of this postoperative arrhythmias. However, extracardiac conduits in the pulmonary ventricleto-pulmonary artery position are known to have a high

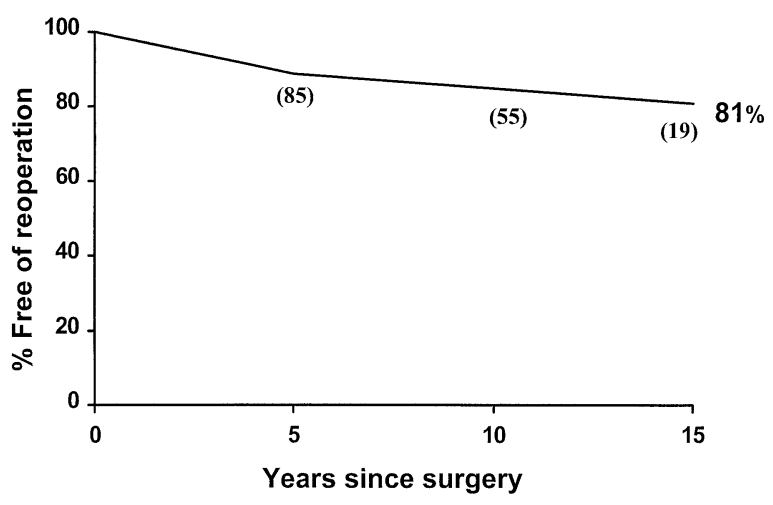

Figure 3. Curve showing freedom from late reoperation in early survivors. $\mathbf{n}=$ number of patients at risk.

incidence of late complications, especially stenosis. The late results of the extracardiac MFP remain to be determined.

The development of late atrial arrhythmias continues to be a significant problem following the MFP. One third of our patients at late follow-up had been or were being treated for atrial arrhythmias. Veldtman and colleagues and Gates and coworkers reported late atrial arrhythmias in $46 \%$ and $37 \%$, respectively in adult patients undergoing the MFP. ${ }^{10,11}$ Late follow-up on large numbers of patients will be necessary to demonstrate which of the many MFP modifications will give the lowest incidence of this important complication. $^{20}$

Four patients had late cerebrovascular accidents, none of whom were on warfarin. Anticoagulation after an MFP continues to be a topic of controversy. ${ }^{21}$ In general, we tend to anticoagulate most adult patients, particularly those with a fenestration or those with a history of arrhythmias, intracardiac thrombus, slow circulation, and venous varices. In the asymptomatic young adult patient, we may substitute aspirin.

Late survival, excluding early mortality, was $89 \%, 75 \%$, and $68 \%$ at 5,10 , and 15 years, respectively. These results are similar to the 61 adult patient series by Veldtman and colleagues in which survival rates of $76 \%, 72 \%$, and $67 \%$ were reported at 5,10 , and 15 years, respectively. ${ }^{10}$ These results are also similar to results of series primarily comprised by pediatric patients as reported by our institution and others. ${ }^{8,22}$ Risk factors for late mortality included preoperative mean pulmonary artery pressures greater than 15 $\mathrm{mm} \mathrm{Hg}$, age greater or equal to 30 years, and male gender. Hemodynamic risk factors in this series were similar to those patients of all ages undergoing the MFP. ${ }^{9,23}$

From the standpoint of symptoms, a marked improvement was noted in most of these adult patients postoperatively. Prior to the MFP, $85 \%$ of patients were in NYHA functional class III or IV. At long-term follow-up, $90 \%$ of survivors were NYHA class I or II. Other series have shown similar results. ${ }^{10,11}$ 
In conclusion, the MFP can be performed with low early mortality in properly selected adult patients with functional single ventricle. Early mortality is more likely with complex lesions. Late survival is good and similar to results reported in children. The majority of late survivors enjoy a good quality of life.

\section{References}

1. Fontan F, Baudet E. Surgical repair of tricuspid atresia. Thorax. 1971;6:240-8.

2. Kreutzer G, Galindez E, Bono H, de Palma C, Laura JP. An operation for correction of tricuspid atresia. J Thorac Cardiovasc Surg. 1973; 66:613-21

3. Kaplan EL, Meier P. Nonparametric estimation from incomplete observations. J Am Stat Assoc. 1958;53:457-81.

4. Cox DR. Regression models and life-tables. JR Stat Soc. 1972;34:187220.

5. Humes RA, Mair DD, Porter CJ, Puga FJ, Schaff HV, Danielson GK. Results of the modified Fontan operation in adults. Am J Cardiol. 1988;61:602-4.

6. Plotkin MV, Mair DD, Puga FJ, Danielson GK. The Fontan procedure in adults: early and late results. [Abstract]. In: Imai Y, Momma K, editors: Proceedings of the Second World Congress of Pediatric Cardiology and Cardiac Surgery; 1997 May 11-15; Honolulu, Hawaii. Armonk [NY]: Futura; 1998. p. 821-2.

7. Choussat A, Fontan F, Besse P, Vallot F, Chauve A, Bricaud H. Selection criteria for Fontan procedure. In: Anderson RH, Shinebourne EA, editors. Pediatric Cardiology. Edinburgh: Churchill Livingstone, 1977. p. 559-66.

8. Driscoll DJ, Offord KP, Feldt RH, Schaff HV, Puga FJ, Danielson GK. Five- to fifteen-year follow-up after Fontan operation. Circulation. 1992;85:469-96.

9. Knott-Craig CJ, Danielson GK, Schaff HV, Puga FJ, Weaver AL, Driscoll DD. The modified Fontan operation: an analysis of risk factors for early postoperative death or takedown in 702 consecutive patients from one institution. J Thorac Cardiovasc Surg. 1995;109: 1237-43.

10. Veldtman GR, Nishimoto A, Siu S, et al. The Fontan operation in adults. Heart. 2001;86:330-5.

11. Gates RN, Laks H, Drinkwater DC, et al. The Fontan operation in adults. Ann Thorac Surg. 1997;63:1085-90.

12. Kirklin JK, Blackstone EH, Kirklin JW, Pacifico AD, Bargeron LM. The Fontan operation. Ventricular hypertrophy, age, and date of operations risk factors. J Thorac Cardiovasc Surg. 1968;92:1049-64.

13. Mair DD, Puga FJ, Danielson GK. The Fontan procedure for tricuspid atresia: early and late results of a 25 -year experience with 216 patients. J Am Coll Cardiol. 2001;37:933-9.

14. Stamm C, Friehs I, Mayer JE, et al. Long-term results of the lateral tunnel Fontan operation. J Thorac Cardiovasc Surg. 2001;121:28-41.

15. Mosca RS, Kulik TJ, Goldberg CS, et al. Early results of the Fontan procedure in one hundred consecutive patients with hypoplastic left heart syndrome. J Thorac Cardiovasc Surg. 2000;119:1110-8.

16. Gaynor JW, Bridges ND, Cohen MI, et al. Predictors of outcome after the Fontan operation: is hypoplastic left heart syndrome still a risk factor? J Thorac Cardiovasc Surg. 2002;123:237-45.

17. Cetta F, Feldt RH, O'Leary PW, et al. Improved early morbidity and mortality after Fontan operation: the Mayo Clinic experience, 1987 to 1992. J Am Coll Cardiol. 1996;28:480-6.

18. Porter CJ, Garson A. Incidence and management of dysrhythmias after Fontan operation. Herz. 1993;18:318-27.

19. Cecchin F, Johnsrude CL, Perry JC, Friedman RA. Effect of age and surgical technique on symptomatic arrhythmias after the Fontan operation. Am J Cardiol. 1995;76:386-91.

20. Durongpisitkul K, Porter CJ, Cetta F, et al. Predictors of early- and late-onset supraventricular tachyarrhythmias after Fontan operation. Circulation. 1998;98:1099-107.

21. Monagle P, Cochrane A, McCrindle B, Benson L, Williams W, Andrew M. Thromboembolic complications after Fontan procedures- the role of prophylactic anticoagulation. J Thorac Cardiovas Surg. 1998; 115:493-8.

22. Fontan F, Kirklin JW, Fernandez G, et al. Outcome after a "perfect" Fontan operation. Circulation. 1990;81:1520-36.

23. Knott-Craig CJ, Schaff HV, Puga FJ, Julsrud PR, Gehring DG, Danielson GK. Therapeutic implications of intraoperative pressure measurements after the Fontan operation. Ann Thorac Surg. 1994;57:937-40.

\section{Discussion}

Dr T. Spray (Philadelphia, $\mathrm{Pa}$ ). I compliment the authors of this excellent paper on their presentation of a large series of adult patients who underwent Fontan reconstruction for variations of single-ventricle anatomy over a 28 -year period in a single institution. The authors have shown very nicely that the Fontan operation can be performed in adult patients with excellent outcomes and improvement in functional status, with mortality and complication rates that are only slightly higher than those seen in the pediatric population. Obviously, patient selection has much to do with the excellent outcomes presented and therefore I have several questions for the authors.

Patients who came to the Fontan completion in this series had class 3 or class 4 symptoms. I assume that most patients had symptoms primarily related to progressive cyanosis rather than heart failure. There have been some centers that have recommended leaving patients with a Glenn anastomosis and not proceeding to a Fontan completion operation, especially in adults.

Your data would suggest that these patients eventually become cyanotic enough to require a Fontan completion. Could you comment on your institutional philosophy regarding the timing of and indications for the completion operation in adult patients?

It is particularly interesting to note that in the series presented, the majority of patients underwent atrial pulmonary operations and relatively fewer adults had the lateral tunnel modification. Only 3 patients in the series underwent an extracardiac completion operation, even though this approach has been preferred in many centers for as long as 10 years and would seem to be ideally suited for those patients who had a previous Glenn anastomosis. Could you comment on why the extracardiac approach has not been used more commonly in your patient population? Is the lateral tunnel technique still the preferred operation at the Mayo Clinic?

Prolonged pleural effusions greater than 2 weeks in duration were noted in about $30 \%$ of the adult population that you presented. Fenestration of the Fontan baffle, however, was only utilized in 2 patients in the series, and yet if cyanosis was the primary indication for operation, a fenestration would still have permitted improvement in oxygen saturation postoperatively and would likely have limited the duration and severity of postoperative effusions.

In your manuscript, which you kindly provided for me prior to this discussion, it was noted that fenestration was used in patients with mild elevation in pulmonary resistance or mildly decreased ejection fraction. Could you elaborate more on what is considered mild elevation of pulmonary resistance or a decrease in ventricular function, considering that the significant majority of your patients had a functional single left ventricle? Would patients with right ventricular morphology have different indications for the complete Fontan operation in your institution in adulthood, and would fenestrations be more commonly used in that patient population? 